\section{Obesity and Endometrial Cancer: Is There a Role for Immunotoxicity?}

\section{Abstract}

Chronic inflammation and obesity are reciprocal pathophysiological processes underlying the element of the immune response. In obesity, alterations of cytokines are thought to contribute to a low grade inflammation within the adipose tissue affecting the development of several secondary diseases. Although micro-inflammation is involved in the initiation of immune response, excessive inflammation may promote tumor development. This review will discuss the reflexive relationship between endometrial cancer and obesity through immunomodulatory effects exerted by environmental chemicals.

Keywords: Environmental chemicals; Obesity; Cytokines; Hypertension
Eftychia Karoutsou ${ }^{1}$, Petros Karoutsos ${ }^{2}$ and Dimitrios Karoutsos ${ }^{3}$

Received: November 04, 2016; Accepted: November 21, 2016; Published: November 28, 2016

\section{Introduction}

Metabolic syndrome is characterized by hypertriglyceridemia, diabetes mellitus, and hypertension and insulin resistance. Obesity is a central player in the pathophysiology of the metabolic syndrome, via the secretion of excessive adipokines. These inflammatory cytokines such as tumor necrosis factor- $\alpha$ and interleukin 6 are elevated in obesity and are counterbalanced by anti- inflammatory cytokines such as adiponectin and visfatin [1]. Adiponectin, protects against liver fibrosis, due to its antiinflammatory effect. On the other hand, inflammatory cytokines, such as tumor necrosis factor-a, decrease insulin release yet being already noxious for the development of fatty liver. For a long time neural and endocrine signals were studied for their impact on adipocyte metabolism and control of storage or release of fatty acids. In fact, bidirectional communication exists between adipocytes and other tissues [2]. Fat cells, through their integrated signals and inflammatory adipokine secretion, are responsible for immune system dysfunction; thereas, a major risk factor for endometrial and other types of cancer. Possible role that lipophilic pollutants stored in abdominal and visceral adipose tissue may play in the lipid metabolism and immunity function regarding the endometrial cancer will be discussed hereafter.

\section{Obesity and Immunity Influential}

Animal models offer important insight into how metabolic abnormalities linked to excess body weight can impair immunity. Diet-induced obese animals, present altered immunological parameters, such as lymphopenia, lower splenic mitogenic
1 Ellinon Axiomaticon 17, Kareas, Athens, Greece

2 Athens Medical Center, Gaia Maternity clinic, Vas Sofias 104, Athens, Greece

3 Department of Obstetrics and Gynecology General Hospital of Rethymno, Athens, Greece

Corresponding author: Eftychia Karoutsou

戸 eutuxiakaroutsou@yahoo.gr

Ellinon Axiomaticon 17, Kareas, Athens, Greece.

Citation: Karoutsou E, Karoutsos P, Karoutsos D. Obesity and Endometrial Cancer: Is There a Role for Immunotoxicity? J Clin Epigenet. 2016, 2:4.

response and a tendency to lower cytotoxic activity of NK cells [35]. In addition, obese pigs, already having impaired metabolism, showed macrophages infiltration. These changes were associated with global DNA hyper methylation in both B-cells and T- cells [6].

Nevertheless, obese individuals show increased risk factors for severe infections and immune system dysfunction that may aggravate the immune response to vaccines [7]. The obese population did not respond to hepatitis B vaccination [8-10] and to tetanus toxoid [11]. Additionally, response to influenza vaccines has been reduced in obese individuals $[12,13]$. Obese individuals present with higher neutrophil, monocyte as well as total leukocyte counts [13] and suppressed lymphocyte responsiveness to mitogens [14-16].

The epigenetic mechanisms that link obesity to cancer seem to be multifactorial and to involve the interplay of metabolic and immune factors; the background behind these associations is only starting to be understood. Insulin resistance is a central player, but there are several other metabolic candidates including insulinlike growth factors and factors released by adipocytes, such as leptin and obesity-related inflammatory markers i.e., tumor necrosis factor- $\alpha$ and interleukin, the nuclear factor kappa beta (NF-KB) system and oxidative stress [17-19]. Obesity is a condition of chronic inflammation characterized by abnormal production 
of inflammatory cytokines with local and systemic effects that can contribute to the development of tumors [19]. Although local limited inflammation may be involved in the initiation of immune responses, excessive inflammation may promote tumor progression in steady-state conditions $[20,21]$.

Of interest, Professor Giovanni De Pergola suggested that central fat accumulation and male gender independently increase the thickness of arterial wall, whereas inflammation and inflammatory markers do not exert an independent effect on this parameter [22]. Abdominal obesity is associated with vascular endothelial dysfunction, caused by reduced nitric oxide availability secondary to an enhanced oxidative stress production. Virdis et al. showed that tumor necrosis factor- $\alpha$ participates on the endothelin-1/ nitric oxide imbalance in small arteries from obese patients, implicating an inflammatory role for perivascular adipose tissue [23]. Notwithstanding, on examining the impact of obesity on treatment outcomes i.e., for prostate cancer, it was found that obesity was associated with higher-grade tumors, a trend towards increasing risk of positive surgical margins and higher biochemical failure rates [24]. Moreover, features of omental adipose tissue in endometrial cancer patients with different obesity phenotype have been associated with the clinical course of endometrial cancer; an inclination to correlation with better tumor differentiation was seen for UCP1 and CD68 protein expression in patients with 'metabolically healthy' obesity [25]. Further, adipose tissue is seen as endocrine organ, synthesizing so called adipocytokines - leptin, adiponectin, visfatin, that play a key role in the carcinogenesis of endometrial cancer and can be used as new markers for establishing the potential risk of this disease [26]. It could be said, that obesity wields impact on the development of vascular diseases, such as atherosclerosis or increases the risk of cancer, via pathways that involve hormonal control, cellular proliferation and even more significant immunity (Table 1).

Table 1 Integrated disease inflammatory signals in response to obesity drive atherosclerosis and increase cancer risk.

\begin{tabular}{|c|c|}
\hline $\begin{array}{c}\text { Immune factors activated by obesity } \\
\text { NLRP, NLRP1, NLRP4 or AIM } 2 \\
\text { inflammasomes }\end{array}$ & $\begin{array}{c}\text { Clinical progression of diseases } \\
\text { such as atherosclerosis or } \\
\text { cancer }\end{array}$ \\
$\begin{array}{c}\text { CCR5 ligand and inflammatory } \\
\text { chemokine MIP-1 }\end{array}$ & $\begin{array}{c}\text { Vascular disease and brain } \\
\text { disorders }\end{array}$ \\
$\begin{array}{c}\text { Increased levels of VEGF and IL-6 } \\
\text { higher proportion of CD8+ T cells and } \\
\text { NKT cells }\end{array}$ & Tumor progression \\
\hline $\begin{array}{c}\text { Activated proinflammatory CD4+ and } \\
\text { CD8+ T cells }\end{array}$ & Oesophageal adenocarcinoma \\
\hline $\begin{array}{c}\text { NF-Kappa B a critical link } \\
\text { Insulin resistance, hyperinsulinaemia, } \\
\text { increased IGF-1 }\end{array}$ & Postmenopausal Breast Cancer \\
\hline $\begin{array}{c}\text { Leptin STAT 3, AP-1, ERK } 2 \text { and MARK } \\
\text { Insulin signalling }\end{array}$ & Colon cancer \\
\hline $\begin{array}{c}\text { Cytokines, ROS, cell stress } \\
\text { The adipokine secretome } \\
\text { upregulation; of proinflammatory } \\
\text { adipokines }\end{array}$ & Cardiovascular diseases \\
\hline
\end{tabular}

'Since the early 1990s, researchers have tested recombinant cytokines, including IL-2, GM-CSF, and interferon, as local and systemic immunotherapies for cancer, in combination with chemotherapy in gene transfer experiments, and in vaccineswith limited success. These cytokines have also been studied for their potential antitumor properties since recombinant cytokines became available in sufficient quantities more than 20 years ago, starting with interferons and IL-2', said Oppenheim [27]. 'Only in the past few years have researchers begun focusing on the role that endogenous cytokines may play in increasing cancer risk' completing his train of thoughts. The pro-inflammatory cytokines can exacerbate the insulin resistance [17], while chronic overproduction by inflammatory cells of reactive oxygen species and cytokines, related to obesity, can induce mutagenic changes and DNA damage triggering cancer development [19]. Additionally as displayed by Frances Balkwill studies of cytokines in the microenvironment [28], certain cytokines are actually cancer-modifying genes. She found in fact that, in human ovarian cancer, the cytokine network is rich in proinflammatory cytokines, growth factors, and chemokines and that TNF- $\alpha$ in particular plays a central role in the microenvironment-in stromal development and regulation of matrix metalloproteinases required for tumor invasion.

\section{What is immunotoxicity?}

The immune system is directly integrated into the organism and interacts intimately with the functioning of many organs and organ systems. Immune function is particularly susceptible to disruption by environmental chemicals. Although major changes in the immune system are rapidly expressed in significant morbidity, and even mortality of the organisms involved, they are often preceded by subtle changes in some of its components that could be used as early tracers or as biomarkers per se [29]; this is of particular interest since these effects generally occur at levels lower than those causing toxic responses of the immune system [30]. But, how environmental chemicals influence the function of the immune system? Do they encumber the role of obesity in increasing cancer risk and what is the case of immunotoxicity and endometrial cancer?

\section{Immunomodulatory Effects by Environ- mental Chemicals}

Chemicals exert effects both at the cellular and the organic level of the immune system [30-33]. Observations in humans and studies in rodents have clearly demonstrated that a number of environmental and industrial chemicals can adversely affect the immune system. Exposure to asbestos, benzene, and halogenated aromatic hydrocarbons such as Polybrominated Biphenyls (PBBs), Polychlorinated Biphenyls (PCBs), and Dioxins (TCDD) can lead to immunosuppression in humans. Classical cytotoxic immunosuppressants act by inhibiting DNA synthesis. Others may act through activation of T-cells or by inhibiting the activation of helper cells [34-40]. While immunosuppression has been brought about in the past primarily to prevent rejection of transplanted organs, new applications involving mediation of the effects of interleukins and other cytokines are emerging [27]. It 
was previously described that obesity, from a pathophysiologic point of view, balances on the edge of a precipice with the inflammation [41,42]; yet specific causal relationships are undetermined in human individuals. Consumption of a saturated fatty acid-rich diet resulted in a proinflammatory 'obesity-linked' gene expression, whereas consumption of a monounsaturated fatty acid-rich diet caused a more anti-inflammatory profile [43]. Dibutyltin (DBT) is known to affect the immune system in nanomolar concentrations; researchers tested the ability of DBT to alter production of cytokines in special immune cells, the macrophages. In this in vitro study, it was found that macrophages exposed to increasing amounts of DBT secreted increasing concentrations of two cytokines, interleukin- 6 and tumor necrosis factor- $\alpha$. Of interest is that in these experiments, DBT inhibited the expression of genes involved in glucose metabolism and in the inflammation response [44]. Indeed [45], there is growing amount of evidence that organotins may be causing irreversible effects on the metabolic and immune systems. Organotins promote adipogenesis in vitro and in vivo [46]. Furthermore, developmental exposure in utero led to a fatty liver phenotype and enhanced lipid staining of neonatal fat depots resulting in a significant increase in the epididymal fat pad size of mice later in life [47]. The next step is the introduction of the term 'obesogen' as representing an environmental pollutant that adversely affects various aspects of adipose tissue functions (Figure 1) [48].

More recently, the concept was extended to include substances that may modify metabolic balance at the hypothalamic level. In mice, TBT (tributyltin) is adipogenic at all ages and in both sexes and that it might be an ER activator in fat cells, These findings might help to resolve the apparent paradox of an adipogenic chemical being also an estrogen receptor activator by showing that the two apparently opposite actions are separated by the different doses to which the organism is exposed $[49,50]$. The environmental 'obesogen' hypothesis predicts that inappropriate receptor activation by organotins will lead directly to adipocyte differentiation and will render exposed individuals susceptible to obesity and immune- related metabolic disorders having already chosen the typical high-calorie, high-fat Western diet [46]. It is postulated that two prime candidate obesogens, tributyltin (TBT) and tetrabromobisphenol A [51], a related to BPA compound, could possibly at high levels of exposure predispose to all endpoints of obesity, such as endometrial cancer [49]. Indeed, BPA exhibited estrogenic activity, but there were remarkable differences. Tetrachlorobisphenol A (TCBPA) showed the highest activity, when being comparatively examined by means of different in vitro and in vivo reporter assays [51]. It was not until recently that gene expression analysis of human endometrial endothelial cells exposed to BPA revealed the paradox of decreased cell proliferation and increased cell death in response to BPA [52], offering important clues to the mechanisms of action of immunomodulating chemicals- a part of the 'obesogen hypothesis'.

\section{Epilogue}

The link that has been proposed between organotins and adipocyte differentiation opens an important new era of research into epigenetics on human health with respect to obesity and emerging diseases such as diabetes or neoplasia. Therefore, additional research directed at understanding the action of chemical obesogens at the receptor level will highlight the connection between obesity and cancer not independent of the exposure dose and may also reveal hidden new mechanisms regulating adipose tissue development. Concluding, immune dismodulation exerted by the environmental chemicals could be the first step in the multistage carcinogenesis.

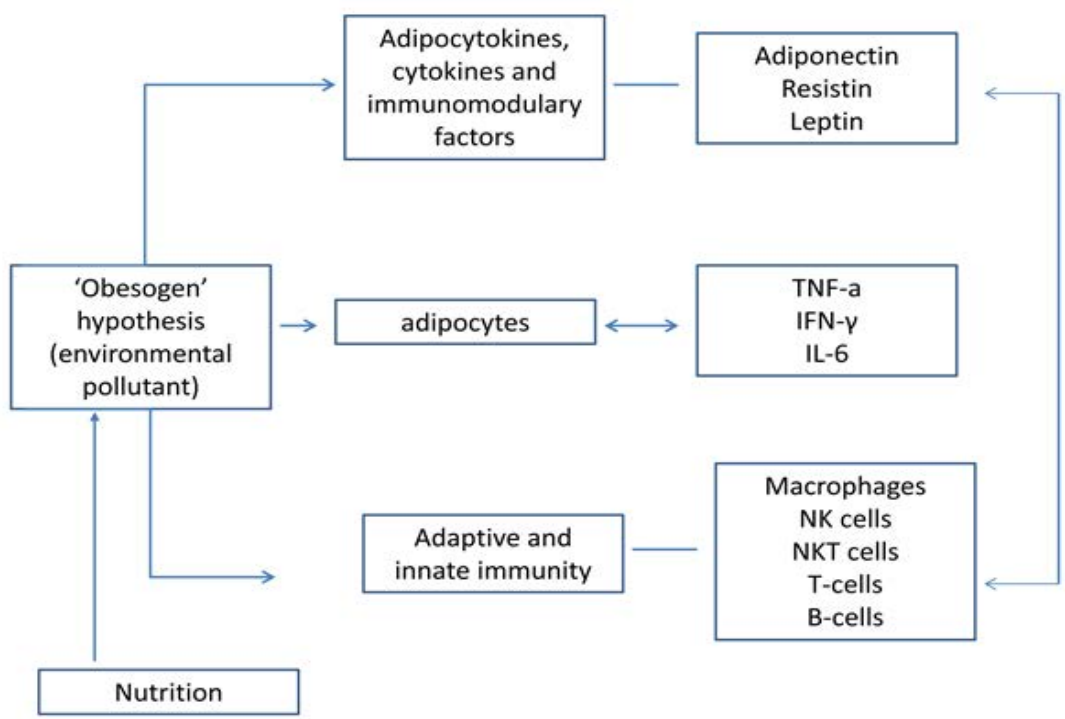

Figure 1 Obesogen represents an environmental pollutant, that adversely affects various aspects of adipose tissue functions. 


\section{References}

1 Richard N, Redinger (2007) Feature Article: The pathophysiology of obesity and its clinical manifestations. Gastroenterol Hepatol 3: 856863.

2 Lafontan M (2005) Fat cells: afferent and efferent messages define new approaches to treat obesity. Annu Rev Pharmacol Toxicol 45: 119-146.

3 Lamas O, Martinez JA, Marti A (2002) T helper lymphopenia and decreased mitogenic response in cafeteria diet-induced obese rats. Nutr Res 22: 496-507.

4 Lamas O, Martínez JA, Marti A (2004) Energy restriction restores the impaired immune response in overweight (cafeteria) rats. J Nutr Biochem 15: 418-425.

5 Katagiri K, Arakawa S, Kurahashi R, Hatano Y (2007) Impaired contact hypersensitivity in diet-induced obese mice. J Dermatol Sci 46: 117 126.

6 Jacobsen MJ, Mentzel CM, Olesen AS, Huby T, Jørgensen CB, et al. (2016) Altered Methylation Profile of Lymphocytes Is Concordant with Perturbation of Lipids Metabolism and Inflammatory Response in Obesity. J Diabetes Res 2016: 8539057

7 Tagliabue C, Principi N, Giavoli C, Esposito S (2016) Obesity: impact of infections and response to vaccines. Eur J Clin Microbiol Infect Dis 35: 325-331.

8 Weber DJ, Rutala WA, Samsa GP, Santimaw JE, Lemon SM (1985) Obesity as a predictor of poor antibody response to hepatitis $B$ plasma vaccine. JAMA 254: 3187-3189.

9 Weber DJ, Rutala WA, Samsa GP, Bradshaw SE, Lemon SM (1986) Impaired immunogenicity of hepatitis $B$ vaccine in obese persons. $N$ Engl J Med 314: 1393.

10 Fan W, Chen XF, Shen C, Guo ZR, Dong C (2016) Hepatitis B vaccine response in obesity: A meta-analysis. Vaccine 34: 4835-4841.

11 Eliakim A, Schwindt C, Zaldivar F, Casali P, Cooper DM (2006) Reduced tetanus antibody titers in overweight children. Autoimmunity 39 : 137-141.

12 Sheridan PA, Paich HA, Handy J, Karlsson EA, Hudgens MG, et al. (2011) Obesity is associated with impaired immune response to influenza vaccination in humans. Int J Obes (Lond) 36: 1027-7.

13 McLarnon A (2011) Obesity: influenza immunity impaired in obesity. Nat Rev Endocrinol 8: 3.

14 Nieman DC, Nehlsen-Cannarella SI, Henson DA, Butterworth DE, Fagoaga OR, et al. (1996) Immune response to obesity and moderate weight loss. Int J Obes Relat Metab Disord 20: 353-360.

15 Tanaka S, Inoue S, Isoda F, Waseda M, Ishihara M, et al. (1993) Impaired immunity in obesity: suppressed but reversible lymphocyte responsiveness. Int J Obes Relat Metab Disord. 17: 631-6.

16 Tanaka S, Isoda F, Ishihara Y, Kimura M, Yamakawa T (2011) T lymphopaenia in relation to body mass index and TNF-a in human obesity: adequate weight reduction can be corrective. Clin Endocrinol 54: 347-354.

17 Chandra RK, Kutty KM (1980) Immunocompetence in obesity. Acta Paediatr Scand 69: 25-30.

18 Calle EE, Kaaks R (2004) Overweight, obesity and cancer: epidemiological evidence and proposed mechanisms. Nat Rev Cancer 4: 579-591.
19 Renehan AG, Roberts DL, Dive C (2008) Obesity and cancer: pathophysiological and biological mechanisms. Arch Physiol Biochem 114: 71-83.

20 Ceschi M, Gutzwiller F, Moch H, Eichholzer M, Probst-Hensch NM (2007) Epidemiology and pathophysiology of obesity as cause of cancer. Swiss Med Wkly 137: 50-56.

21 Kim R, Emi M, Tanabe K (2007) Cancer immunoediting from immune surveillance to immune escape. Immunology 121: 1-14.

22 De Pergola G, Ciccone MM, Guida P, Morea G, Giannuzzo E, et al. (2011) Relationship between C3 levels and common carotid intimamedia thickness in overweight and obese patients. Obes Facts 4: 159-163.

23 Virdis A, Duranti E, Rossi C, Dell'Agnello U, Santini E, et al. (2015) Tumour necrosis factor-alpha participates on the endothelin-1/ nitric oxide imbalance in small arteries from obese patients: role of perivascular adipose tissue. Eur Heart J 36: 784-794.

24 Freedland SJ, Aronson WJ, Kane CJ, Presti JC Jr, Amling CL, et al. (2004) Impact of obesity on biochemical control after radical prostatectomy for clinically localized prostate cancer: a report by the Shared Equal Access Regional Cancer Hospital database study group. J Clin Oncol 22: $446-453$

25 Berstein LM, Iyevleva AG, Mukhina MS, Vasilyev DA, Poroshina TE (2016) Features of omental adipose tissue in endometrial cancer patients with 'standard' or 'metabolically healthy' obesity: associations with tumor process characteristics. Springerplus 5: 1900.

26 Uchikova E, Uchikov P, Parahuleva P (2015) Obesity and Endometrial Carcinogenesis. Akush Ginekol (Sofiia) 54: 34-37.

27 Oppenheim J (2005) Researchers attempting to define role of cytokines in cancer risk. J Natl Cancer Inst 97: 1175-1177.

28 Balkwill F (2005) Researchers attempting to define role of cytokines in cancer risk. J Natl Cancer Inst 97: 1175-1177.

29 Dean JH, Murray MJ (1990) Toxic responses of the immune system. In Toxicology: The Basic Science of Poisons. Macmillan, New York, pp: 282-333.

30 Koller LD, Exon JH (1985). The rat as a model for immunotoxicity assessment. In Immunotoxicology and Immunopharmacology, pp: 99-111.

31 Descotes J (1988) Immunotoxicity of chemicals. In: Immunotoxicology of Drugs and Chemicals. Elsevier, Amsterdam, pp: 297-444.

32 Luster M, Portier C, Pait DG, Germolec DR (1994) Use of animal studies in risk assessment for immune toxicology. Toxicology 92 229-243.

33 Trizio D, Basketter DA, Botham PA, Graepel PH, Lambré C, et al. (1988) Identification of immunotoxic effects of chemicals and assessment of their relevance to man. Food Chem Toxicol 26: 527-539.

34 Wong S, Fournier M, Coderre D, Banska W, Krzystyniak K (1992) Environmental immunotoxicology. In Animal Biomarkers as Pollution Indicators. Chapman and Hall, London pp: 167-189.

35 Holladay SD, Luster M (1996) Chemically-Induced Alterations in the Developing Immune System: The Wildlife/Human Connection. Environmental Health Perspectives 104: 809- 814.

36 Krzystyniak K (1995) Approaches to the Evaluation of Chemical Induced Immunotoxicity. Environ Health Perspect 203: 17-23.

37 Luster MI (1996) Immunotoxicology: clinical consequences. Toxicol Ind Health 12: 533-535. 
38 Luster MI, Rosenthal GJ (1993) Chemical agents and the immune response. Environ Health Perspect 100: 219-226.

39 Office of Technology Assessment (1991) Identifying and Controlling Immunotoxic Substances. Washington, DC: Government Printing Office.

40 Thomas PT (1995) Pesticide-induced immunotoxicity: are Great Lakes residents at risk? Environ Health Perspect 103: 55-61.

41 Pickup JC, Mattock MB, Chusney GD, Burt D (1997) NIDDM as a disease of the innate immune system: association of acute-phase reactants and interleukin- 6 with metabolic syndrome $X$. Diabetologia 40: 1286-1292.

42 Bistrian BR, Khaodhiar L (2000) Chronic systemic inflammation in overweight and obese adults. JAMA 283: 2235.

43 van Dijk SJ, Feskens EJ, Bos MB, Hoelen DW, Heijligenberg R, et al. (2009) A saturated fatty acid-rich diet induces an obesity-linked proinflammatory gene expression profile in adipose tissue of subjects at risk of metabolic syndrome. Am J Clin Nutr 90: 1656-1664.

44 Gumy C, Chandsawangbhuwana C, Dzyakanchuk AA, Kratschmar DV, Baker ME, et al. (2008) Dibutyltin Disrupts Glucocorticoid Receptor Function and Impairs Glucocorticoid-Induced Suppression of Cytokine Production. PLoS ONE 3: 3545.

45 Yano K, Ohno S, Nakajima Y, Toyoshima S, Nakajin S (2003) Effects of Various Chemicals Including Endocrine Disruptors and Analogs on the Secretion of Th1 and Th2 Cytokines from Anti CD3-Stimulated Mouse Spleen Cells. J Health Sci 49: 195-204.

46 Grün F, Blumberg B (2006) Environmental obesogens: organotins and endocrine disruption via nuclear receptor signaling. Endocrinology 147: $50-55$.

47 Grün F, Watanabe H, Zamanian Z, Maeda L, Arima K, et al. (2006) Endocrine-disrupting organotin compounds are potent inducers of adipogenesis in vertebrates. Mol Endocrinol 20: 2141-2155.

48 Inadera $\mathrm{H}$, Shimomura A (2005) Environmental chemical tributyltin augments adipocyte differentiation. Toxicol Lett 159: 226-234.

49 Penza M, Jeremic M, Marrazzo E, Maggi A, Ciana P, et al. (2011) The environmental chemical tributyltin chloride (TBT) shows both estrogenic and adipogenic activities in mice which might depend on the exposure dose. Toxicol Appl Pharmacol 255: 65-75.

50 Decherf S, Demeneix BA (2011) The obesogen hypothesis: a shift of focus from the periphery to the hypothalamus. J Toxicol Environ Health B Crit Rev 14: 423-448.

51 Kitamura S, Suzuki T, Sanoh S, Kohta R, Jinno N, et al. (2005) Comparative study of the endocrine-disrupting activity of bisphenol A and 19 related compounds. Toxicol Sci 84: 249-259.

52 Bredhult C, Sahlin L, Olovsson M (2009) Gene expression analysis of human endometrial endothelial cells exposed to Bisphenol $A$. Reprod Toxicol 28: 18-25. 